\title{
Pengaruh Bandara Internasional Jenderal Ahmad Yani Semarang Terhadap Kinerja Akses Jalan Di Sekitar Bandara
}

\author{
(Studi Kasus: Jalan Madukoro, Jalan Yos Sudarso, \\ Jalan Puri Anjasmoro Raya, Jalan Puri Eksekutif)
}

\author{
Aloysius H G Daika1, Tua Ebenezer Tampubolon², Djoko Setijowarno ${ }^{3}$, Djoko Suwarno ${ }^{4}$ \\ email: ${ }^{1}$ business.alsius@gmail.com, ${ }^{2}$ ebentampubolon08@gmail.com \\ Program Studi Teknik Sipil, Fakultas Teknik, Universitas Katolik Soegijapranata \\ Jl. Pawiyatan Luhur IV/1, Bendan Dhuwur, Semarang 50234
}

\begin{abstract}
Abstrak
Semarang merupakan salah satu kota yang besar di Indonesia dengan jumlah penduduk yang mencapai lebih dari satu juta jiwa. Dengan kepadatan penduduk yang jumlahnya cukup besar tentu berdampak terhadap transportasi dan lalu lintas, baik transportasi darat, laut, maupun udara. Pada tahun 2018 kemarin, Pemerintah Kota Semarang telah selesai membangun terminal baru Bandara Jenderal Ahmad Yani Semarang yang telah diresmikan juga oleh Bapak Presiden Republik Indonesia dan mulai beroperasi bulan Juni tahun 2018 yang lalu. Oleh karena itu, kami sebagai penulis mecoba untuk menganalisis kinerja akses jalan yang ada di sekitar Bandara Jenderal Ahmad Yani Semarang sebelum dan sesudah bandara yang baru beroperasi. Ada empat jalan yang menjadi objek penelitian yaitu Jalan Madukoro, Jalan Yos Sudarso, Jalan Puri Anajasmoro Raya, serta Jalan Puri Eksekutif. Metode yang digunakan pada penelitian ini adalah penelitian langsung di lapangan, setelah mendapatkan data volume lalu lintas yang diperoleh kemudian dianalisis berdasarkan peraturan Departemen Pekerjaan Umum tentang Manual Kapasitas Jalan Indonesia (1997). Berdasarkan hasil analisis yang telah dibahas, maka didapat hasil sebagai berikut: nilai derajat kejenuhan (DS) pada masa sekarang untuk masing- masing ruas jalan adalah 0,63 di Jalan Madukoro termasuk dalam tingkat pelayanan kategori C; 0,67 di Jalan Yos Sudarso termasuk dalam tingkat pelayanan kategori C; 0,71 di Jalan Puri Anjasmoro Raya termasuk dalam tingkat pelayanan kategori C; 0,08 di Jalan Puri Eksekutif termasuk dalam tingkat pelayanan kategori A. Kemudian kinerja akses jalan yang berada di sekitar Bandara Jenderal Ahmad Yani Semarang masih berada dalam kondisi arus yang stabil, karena nilai derajat kejenuhan (DS) di masing-masing akses jalan yang menjadi objek penelitian kurang dari satu. Akses jalan yang memiliki tingkat pelayanan terbaik adalah Jalan Puri Eksekutif dengan tingkat pelayanan kategori A, artinya kondisi arus bebas karena volume lalu lintas yang rendah. Pengemudi dapat memilih kecepatan yang diinginkan tanpa hambatan.
\end{abstract}

Kata Kunci : Bandara, Kinerja Akses Jalan, Volume Lalu Lintas

\begin{abstract}
Semarang is one of the big cities in Indonesia with a population of more than one million. With a population density that is quite large, it certainly has an impact on transportation and traffic, both land, sea and air transportation. In 2018, the Semarang City Government has finished building a new terminal at Semarang General Ahmad Yani Airport which was also inaugurated by the President of the Republic of Indonesia and began operating in June 2018 ago. Therefore, we as authors try to analyze the performance of road access around Semarang's General Ahmad Yani Airport before and
\end{abstract}


after the newly operating airport. There are four roads that are the object of research, namely Madukoro Street, Yos Sudarso Street, Puri Anajasmoro Raya Street, and Puri Eksekutif Street. The method used in this study is direct research in the field, after obtaining the traffic volume obtained then analyzed based on the Department of Public Works regulations on the Indonesian Road Capacity Manual (1997). Based on the results of the analysis discussed, the following results are obtained: the degree of degree of saturation (DS) in the present for each road segment is 0,63 on Madukoro Street included in the service level of category C; 0,67 on Yos Sudarso Street is included in the category C service level; 0,71 at Puri Anjasmoro Raya Street is included in the category C service level; 0,08 on Puri Eksekutif Street is included in the category A service level. Then the road access performance around Semarang General Ahmad Yani Airport is still in a stable current condition, because the value of degree of saturation $(D S)$ in each road access becomes less than one research object.

Keywords : Airports, Road Access Performance, Traffic Volume.

\section{PENDAHULUAN}

Kota Semarang merupakan Ibu Kota Provinsi Jawa Tengah. Sebagai Ibu Kota Provinsi, Kota Semarang menjadi pusat kegiatan, baik kegiatan sosial budaya, kegiatan pemerintahan, kegiatan perdagangan, kegiatan pendidikan dan lain-lain. Hal ini menyebabkan banyak warga desa atau kabupaten lain yang pindah bahkan menetap di kota untuk bekerja dan sekolah. Diketahui jumlah penduduk di Kota Semarang kini mencapai 1.815.729 jiwa (BPS, 2018) jumlah ini diperkirakan akan terus bertambah setiap tahunnya. Meningkatnya jumlah penduduk di kota Semarang berdampak pada meningkatnya berbagai kebutuhan salah satunya kebutuhan akan trasportasi untuk mendukung kelancaran suatu kegiatan.

Perkembangan pesat pun terjadi di dunia penerbangan di Kota Semarang dan seiring dengan hal tersebut permintaan penyediaan tempat trasportasi yang memadai dan layak pun turut meningkat. Aktifitas bandara terutama pada jam operasional kerja secara langsung akan mempengaruhi kelancaran lalu lintas di sekitar bandara. Terganggunya kelancaran lalu lintas ini disebabkan oleh aktifitas keluar masuknya kendaraan dari atau menuju bandara dan hambatan samping yang menyebabkan berkurangnya lebar efektif badan jalan, turunnya kinerja ruas jalan, konflik lalu lintas dan meningkatnya hambatan atau delay. Berdasarkan Perda Kota Semarang No. 3 Tahun 2016 pasal 4 huruf d, mengidentifikasi masalah-masalah yang dapat mempengaruhi putusan pengembang atau pembangun dalam meneruskan rencana pembangunan pusat kegiatan, permukiman dan infrastruktur yang diusulkan.

Beberapa jaringan jalan yang ada di sekitar bandara dikembangkan untuk melayani dan menghubungkan antar daerah di Kota Semarang menuju bandara. Hal ini dapat dilihat dari jalan Madukoro, Yos Sudarso, Puri Anjasmoro, dan Puri Eksekutif yang memiliki peran vital dalam lalu lintas di Kota Seamarang di mana ke empat ruas jalan ini memiliki kondisi lapangan yang berbeda. Pada ruas jalan Madukoro khususnya di persimpangan (4 simpang jalan Yos Sudarso dan Madukoro) arah menuju bandara, Puri Anjasmoro Raya tersebut sering mengalami permasalahan lalu lintas seperti peningkatan tundaan saat jam puncak atau jam sibuk karena tingginya aktifitas masyarakat diikuti oleh kegiatan 
truk pengantar barang yang menggunakan simpang di jalan Madukoro sebagai akses menuju Pekalongan, Boja, Kendal, Jakarta, dll pada saat yang bersamaan, ditambah lagi hambatan samping yang muncul akibat kendaraan yang mengantar atau menjemput di bandara.

Untuk memperbaiki kinerja jalan yang semakin padat tersebut, maka perlu adanya suatu studi yang bermaksut untuk mengetahui kinerja ruas jalan pada lokasi studi dengan adanya terminal baru Bandara Internasional Jenderal Ahmad Yani Semarang dibandingkan bila tanpa Bandara Internasional Jenderal Ahmad Yani Semarang. Studi ini diperlukan untuk mengidentifikasi masalah di beberapa ruas jalan di sekitar bandara agar nantinya dapat menemukan solusi yang tepat untuk mencegah terjadinya masalah lalu lintas yang lebih besar.

\section{TINJAUAN PUSTAKA}

Perencanaan sistem transpotasi pada dasarnya memperkirakan kebutuhan transportasi di masa mendatang. Dalam sistem transportasi terdapat 4 sub sistem yang saling berkaitan satu dengan yang lainnya (Tamin, 2000). Adapun keempat sub sistem tersebut yaitu sistem pergerakan lalu lintas, sistem kegiatan transportasi, sistem sarana dan prasarana transportasi, serta sistem kelembagaan.

Menurut Departemen Pekerjaan Umum (1997), arus lalu lintas merupakan jumlah kendaraan bermotor yang melalui titik pada jalan per satuan waktu, dinyatakan dalam kend/jam (Qkend), smp/jam (Qsmp) atau LHRT (Lalu Lintas Harian Rata-rata Tahunan). Dalam manual kapasitas, nilai arus lalu lintas (Q) mencerminkan komposisi lalu lintas, dengan menyatakan arus dalam satuan mobil penumpang (smp). Semua nilai arus lalu lintas (per arah dan total) diubah menjadi satuan mobil penumpang (smp) dengan menggunakan ekivalen mobil penumpang (emp) yang diturunkan secara empiris dengan 3 tipe kendaraan yaitu sepeda motor (MC), kendaraan ringan (LV), dan kendaraan berat (HV).

Volume lalu lintas adalah banyaknya kendaraan yang melewati suatu titik atau garis tertentu pada suatu penampang melintang jalan. Data pencacahan volume lalu lintas adalah informasi yang diperlukan untuk fase perencanaan, desain, manajemen sampai pengoperasian jalan (Sukirman, 1994). Menurut Sukirman (1994), volume lalu lintasmenunjukan jumlah kendaraan yang melintasi satu titik pengamatan dalam satu satuan waktu (hari, jam, menit). Sehubungan dengan penentuan jumlah dan lebar jalur, satuan volume lalu lintas yang umum dipergunakan adalah lalu lintas harian rata-rata, volume jam perencanaan dan kapasitas. Jenis kendaraan dalam perhitungan ini diklasifikasikan dalam 3 macam kendaraan, yaitu kendaraan ringan (Light Vechicles $=$ LV), kendaraan berat (Heavy Vechicles $=\mathrm{HV}$ ), dan sepeda motor (Motor Cycle $=\mathrm{MC}$ ). Sedangkan untuk kendaraan tak bermotor (sepeda, becak dan kereta dorong), dan pejalan kaki dianggap sebagai hambatan samping. Data jumlah kendaraan kemudian dihitung dalam kendaraan/jam untuk setiap kendaraan, dengan faktor koreksi masingmasing kendaraan yaitu $\mathrm{MC}=0,25 ; \mathrm{LV}=$ 1,0; HV = 1,2 (MKJI, 1997). Berdasarkan UU No. 38 tahun 2004, jalan sebagai sarana transportasi mempunyai peranan penting dalam bidang ekonomi, 3ocial budaya, lingkungan hidup, politik, pertahanan dan kemananan serta digunakan sebesar-besarnya untuk kemakmuran rakyat. Jalan dapat 
diklasifikasikan menjadi dua yaitu jalan umum dan jalan khusus.

Menurut Manual Kapasitas Jalan Indonesia (1997), kapasitas jalan merupakan arus lalu lintas maksimum yang dapat melintas dengan stabil pada suatu potongan melintang jalan pada kondisi tertentu. Ada tiga faktor yang berhubungan dengan kapasitas jalan, antara lain kapasitas dasar (Co), faktor penyesuaian pemisah arah (FCSP), faktor penyesuaian lebar jalur lalu lintas ( $\mathrm{FCw})$, faktor penyesuaian hambatan samping (FCSF), serta faktor penyesuaian ukuran kota.

Tingkat pelayanan merupakan indikator yang dapat mencerminkan tingkat kenyamanan ruas jalan, yaitu perbanmdingan antara volume lalu lintas yang ada terhadap kapasitas jalan tersebut (Departemen Pekerjaan Umum, 1997). Tingkat pelayanan jalan ditentukan dalam suatu skala interval yang terdiri dari 6 tingkat. Tingkat-tingkat ini dinyatakan dalam huruf A yang merupakan tingkat pelayanan tertinggi sampai dengan huru $\mathrm{F}$ yang merupakan tingkat pelayanan paling rendah.

Menurut Sugeng, (2018), rate of flow (angka aliran) merupakan jumlah kendaraan yang dapat melalui suatu penampang jalan atau lajur jalan pada interval waktu tertentu (biasanya kurang dari 1 jam), misalnya 15 menit. Hubungan antara volume setiap jam dan angka aliran maksimum (Maximum Rate of Fow) dalam jam tersebut dinyatakan dengan faktor jam puncak (Peak Hour Factor $=$ PHF). PHF $=$ Hourly Volume $/$ Maximum Rate of Fow.

\section{HASIL DAN PEMBAHASAN}

Pada penelitian ini, yang dijadikan sebagai lokasi studi yaitu jalan utama menuju bandara Interasional Jendral Ahmad Yani Semarang. Lokasi ini dipilih karena pada ruas jalan menuju bandara tersebut masih dalam tahap penyesuaian untuk menuju bandara, dikarenakan pembangunan adanya bandara baru, maka tidak menutup kemungkinan terjadi masalah lalu lintas yang menyebabkan turunnya kinerja ruas jalan. Ada 4 jalan yang menjadi lokasi studi, antara lain:

1. Jalan Madukoro

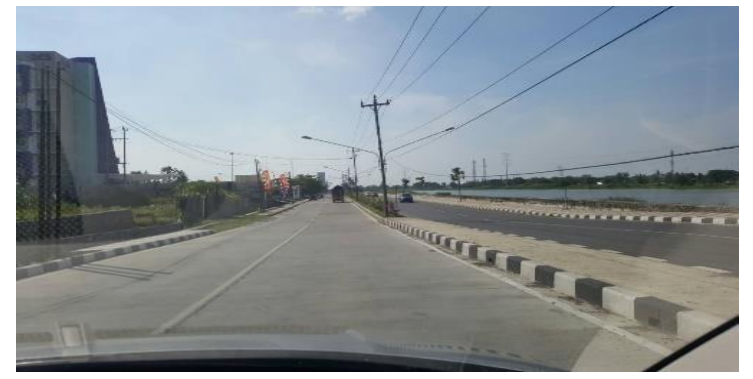

Gambar 3.1 Lokasi Studi di Jalan Madukoro

(Sumber: Hasil Survei, tahun 2018)

2. Jalan Yos Sudarso

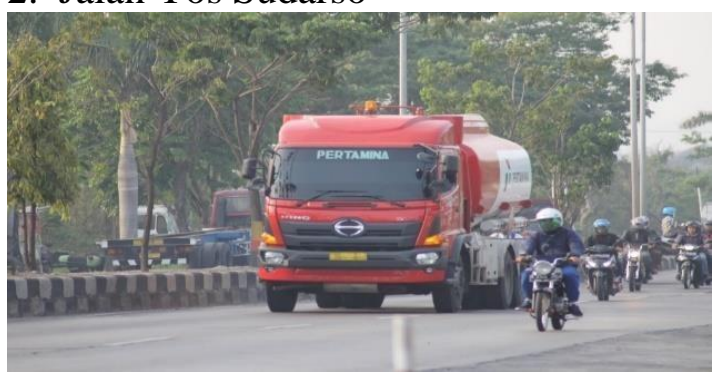

Gambar 3.2 Lokasi Studi di Jalan Yos Sudarso

(Sumber: Hasil Survei, tahun 2018)

3. Jalan Puri Anjasmoro Raya

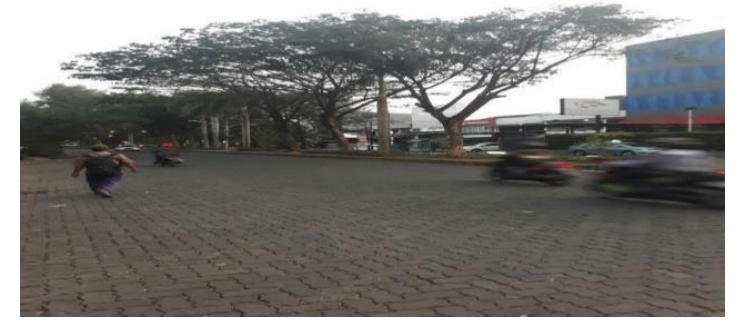

Gambar 3.3 Lokasi Studi di Jalan Puri Anjasmoro Raya

(Sumber: Hasil Survei, tahun 2018) 
4. Jalan Puri Eksekutif

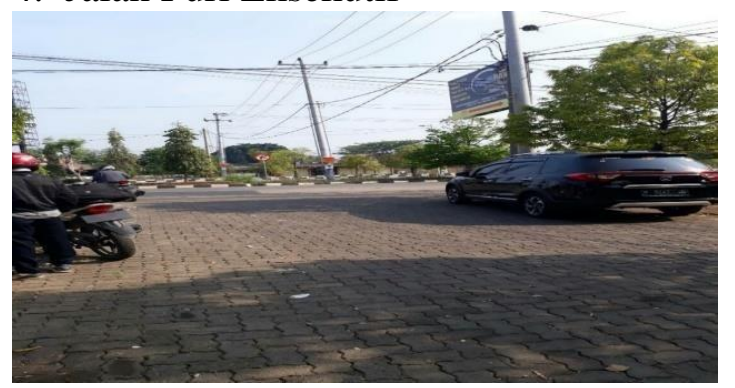

Gambar 3.4 Lokasi Studi di Jalan Puri Eksekutif

(Sumber: Hasil Survei, tahun 2018)

Pengumpulan data merupakan hal yang penting dalam sebuah penelitian. Pada penelitian ini, data yang digunakan hanya satu jenis data, yaitu data primer primer saja.

Data primer merupakan data yang diperoleh langsung dengan cara mengadakan survei di lapangan. Dalam survei ini, pengumpulan data primer dilakukan dengan metode manual di lapangan yang meliputi data inventaris jalan, hambatan samping, serta volume kendaraan.

\section{Survei Inventaris Jalan}

Survei invetaris jalan dilakukan untuk mengetahui kondisi yang ada pada daerah studi. Metode yang digunakan dalam survei ini adalah pengukuran langsung dengan menggunakan meteran. Survei dilakukan oleh dua orang, yaitu satu orang melakukan pengukuran dan satu orang melakukan pencatatan hasil pengukuran. Alat survei yang diperlukan adalah formulir survei yang sudah diformat, alat tulis, meteran dan papan kerja. Data yang dikumpulkan berkaitan dengan desain geometrik jalan yang diinventarisasikan adalah lebar jalan, median, bahu jalan serta trotoar.

2. Hambatan Samping

Survei hambatan samping diperlukan untuk mencari kapasitas berdasarkan Departemen Pekerjaan Umum (1997), dimana survei ini dilaksanakan pada jam sibuk. Dalam survei hambatan samping terdapat beberapa ketentuan, antara lain:

a.) Indikator pengamatan, yang meliputi:

1. Jumlah kendaraan berhenti dan parkir,

2. Jumlah kendaraan bermotor yang masuk dan keluar ke/dari lahan samping jalan dan sisi jalan,

3. Jumlah kendaraan tak bemotor (sepeda, becak, delman, dll),

4. Jumlah pejalan kaki yang berjalan b.) Peralatan surveyor dalam pelaksanaan survei dilengkapi dengan stopwatch (alat ukur waktu), formulir survei, alat tulis dan papan kerja.

c.) Metode survei, yang meliputi:

1. Pencatatan dilakukan secara manual,

2. Survei yang dilakukan oleh dua orang surveyor, pencatatan dilakukan selama 15 menit untuk 1 kali pencatatan.

3. Survei Volume Lalu Lintas Pengumpulan data volume lalu lintas dilakukan dengan metode manual count yaitu perhitungan volume lalu lintas dengan cara sederhana, menghitung setiap kendaraan yang melewati suatu titik pengamatan pada ruas jalan. Survai ini dilakukan pada ruas-ruas jalan disekitar bandara yang mendapat pengaruh akibat aktivitas di bandara Internasional Jenderal Ahmad Yani Semarang.

Peralatan survei, pelaksanaan survei dan data yang dicatat dijelaskan sebagai berikut:

a.) Pelaksanaan survei berlokasi di jalan Madukoro, jalan Yos Sudarso, jalan Puri Anjasmoro Raya, serta jalan Puri Eksekutif, di mana ke empat akses jalan ini merupakan jalan yang terpengaruh oleh aktivitas yang terjadi di Bandara 
Internasional Jenderal Ahmad Yani Semarang. Survei ini dilakukan selama 3 jam bertahap.

b.) Data yang dicatat berupa banyaknya kendaraan yang melewati titik pengamatan seperti kendaraan ringan, kendaraan berat, sepeda motor dan kendaraan tidak bermotor.

c.) Peralatan survei yang digunakan adalah formulir survei yang sudah diformat, alat ukur waktu, alat tulis dan papan kerja.

d.) Metode pengumpulan data; surveyor yang diperlukan sebanyak dua orang. Surveyor menempati suatu titik yang sudah ditetapkan pada tepi jalan yang bertujuan agar surveyor memiliki pandagan yang jelas mengenai kendaraan yang akan diamati. Surveyor mencatatat setiap kendaraan yang melewati titik pengamatan pada formulir survei. Pengamatan dilakukan secara terpisah untuk masing-masing arah lalu lintas dan jenis kendaraan pada interval waktu yang sudah ditentukan yaitu 15 menit. Kemudian data yang sudah diperoleh dijumlahkan pada tahap analisis data.

\section{Bagan Alir}

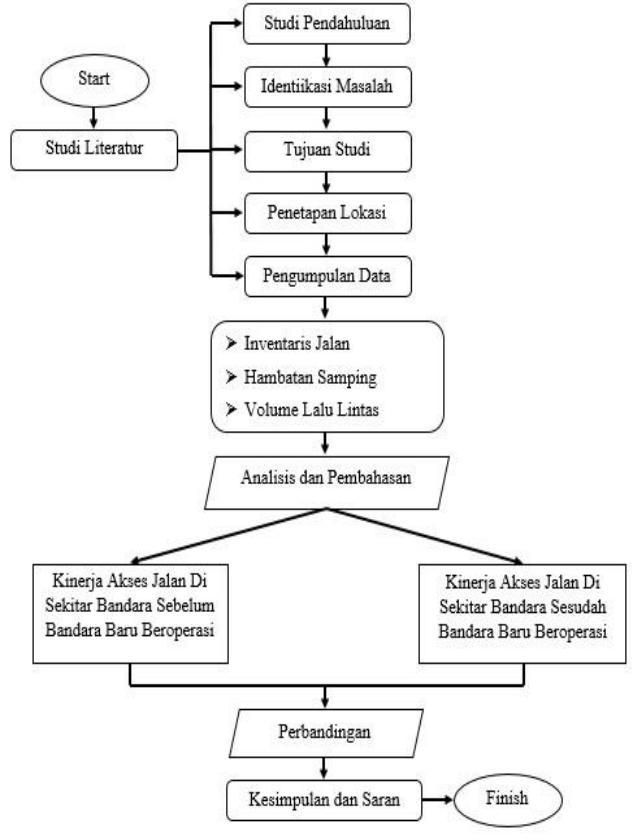

\section{HASIL DAN PEMBAHASAN}

Berikut ini merupakan hasil dan pembahasan dari hasil survei dan penelitian:

\subsection{Pengolahan Data}

Data primer yang berasal dari hasil survei di lapangan dan data sekunder yang diperoleh dari instansi terkait, merupakan data mentah yang selanjutnya akan disusun terlebih dahulu untuk kemudian dianalisis.

\subsubsection{Inventaris Jalan}

Tabel 4.1 Data Inventaris Jalan Madukoro

\begin{tabular}{|c|c|}
\hline Tipe Jalan & Empat lajur terbagi (4/2 D) \\
\hline Jenis & Beton \\
\hline Lebar Jalur & $7 \mathrm{~m}$ \\
\hline Lebar Lajur & $3,5 \mathrm{~m}$ \\
\hline Lebar Bahu & $1,5 \mathrm{~m}$ \\
\hline
\end{tabular}

(Sumber: Hasil Survei, tahun 2018)

Tabel 4.2 Data Inventaris Jalan Yos Sudarso

\begin{tabular}{|c|c|}
\hline Tipe Jalan & Empat lajur terbagi (4/2 D) \\
\hline Jenis Perkerasan & Aspal \\
\hline Lebar Jalur & $8 \mathrm{~m}$ \\
\hline Lebar Lajur & $4 \mathrm{~m}$ \\
\hline Lebar Bahu Jalan & $1,5 \mathrm{~m}$ \\
\hline
\end{tabular}

(Sumber: Hasil Survei, tahun 2018)

Tabel 4.3 Data Inventaris Puri Anjasmoro

\begin{tabular}{|c|c|}
\hline Tipe Jalan & Empat lajur terbagi (4/2 D) \\
\hline Jenis & Paving Block \\
\hline Lebar Jalur & $7 \mathrm{~m}$ \\
\hline Lebar Lajur & $3,5 \mathrm{~m}$ \\
\hline Lebar Bahu & $1 \mathrm{~m}$ \\
\hline
\end{tabular}

(Sumber: Hasil Survei, tahun 2018)

Tabel 4.4 Data Inventaris Jalan Puri Eksekutif

\begin{tabular}{|c|c|}
\hline Tipe Jalan & Empat lajur terbagi (4/2 D) \\
\hline Jenis Perkerasan & Paving Block \\
\hline
\end{tabular}




\begin{tabular}{|c|c|}
\hline Lebar Jalur & $6 \mathrm{~m}$ \\
\hline Lebar Lajur & $3 \mathrm{~m}$ \\
\hline Lebar Bahu Jalan & $0,5 \mathrm{~m}$ \\
\hline
\end{tabular}

(Sumber: Hasil Survei, tahun 2018)

\subsubsection{Volume Lalu Lintas}

Tabel 4.5 Distribusi Volume Lalu Lintas di Jalan Madukoro

\begin{tabular}{|c|c|c|c|c|}
\hline \multicolumn{2}{|c|}{ Periode Waktu } & MC & LV & HV \\
\hline \multirow{2}{*}{ Senin } & $05.00-08.00$ & 2358 & 1082 & 29 \\
\cline { 2 - 5 } & $15.00-18.00$ & 3545 & 1586 & 43 \\
\hline \multirow{2}{*}{ Rabu } & $05.00-08.00$ & 2130 & 1026 & 24 \\
\cline { 2 - 5 } & $15.00-18.00$ & 2980 & 1584 & 29 \\
\hline \multirow{2}{*}{ Jumat } & $05.00-08.00$ & 2775 & 1223 & 34 \\
\cline { 2 - 5 } & $15.00-18.00$ & 3621 & 1629 & 65 \\
\hline
\end{tabular}

(Sumber: Hasil Survei, tahun 2018)

Tabel 4.6 Distribusi Volume Lalu Lintas di Jalan Yos Sudarso

\begin{tabular}{|c|c|c|c|c|}
\hline \multicolumn{2}{|c|}{ Periode Waktu } & MC & LV & HV \\
\hline \multirow{2}{*}{ Senin } & $05.00-08.00$ & 3159 & 1213 & 104 \\
\cline { 2 - 5 } & $15.00-18.00$ & 4548 & 1661 & 251 \\
\hline \multirow{2}{*}{ Rabu } & $05.00-08.00$ & 2539 & 1097 & 84 \\
\cline { 2 - 5 } & $15.00-18.00$ & 3649 & 1544 & 205 \\
\hline \multirow{2}{*}{ Jumat } & $05.00-08.00$ & 2816 & 1153 & 95 \\
\cline { 2 - 5 } & $15.00-18.00$ & 3865 & 1553 & 232 \\
\hline
\end{tabular}

(Sumber: Hasil Survei, tahun 2018)

Tabel 4.7 Distribusi Volume Lalu Lintas di Jalan Puri Anjasmoro Raya

\begin{tabular}{|c|c|c|c|c|}
\hline \multicolumn{2}{|c|}{ Periode Waktu } & MC & LV & HV \\
\hline \multirow{2}{*}{ Senin } & $05.00-08.00$ & 1899 & 701 & 41 \\
\cline { 2 - 5 } & $15.00-18.00$ & 2735 & 1350 & 78 \\
\hline \multirow{2}{*}{ Rabu } & $05.00-08.00$ & 1768 & 626 & 43 \\
\cline { 2 - 5 } & $15.00-18.00$ & 2491 & 1297 & 76 \\
\hline \multirow{2}{*}{ Jumat } & $05.00-08.00$ & 1984 & 719 & 44 \\
\cline { 2 - 5 } & $15.00-18.00$ & 2938 & 1359 & 92 \\
\hline
\end{tabular}

(Sumber: Hasil Survei, tahun 2018)
Tabel 4.8 Distribusi Volume Lalu Lintas di Jalan Puri Eksekutif

\begin{tabular}{|c|c|c|c|c|}
\hline \multicolumn{2}{|c|}{ Periode Waktu } & MC & LV & HV \\
\hline \multirow{2}{*}{ Senin } & $05.00-08.00$ & 154 & 115 & 0 \\
\cline { 2 - 5 } & $15.00-18.00$ & 284 & 219 & 0 \\
\hline \multirow{2}{*}{ Rabu } & $05.00-08.00$ & 133 & 111 & 0 \\
\cline { 2 - 5 } & $15.00-18.00$ & 246 & 203 & 0 \\
\hline \multirow{2}{*}{ Jumat } & $05.00-08.00$ & 149 & 108 & 0 \\
\cline { 2 - 5 } & $15.00-18.00$ & 264 & 209 & 0 \\
\hline
\end{tabular}

(Sumber: Hasil Survei, tahun 2018)

\subsection{Analisis Kinerja Ruas Jalan Saat Ini Pada Jam Puncak Volume Lalu Lintas}

Untuk menganalisis kinerja ruas jalan saat ini dibutuhkan analisis volume lalu lintas serta kapasitas ruas jalan berdasarkan parameter- parameter yang sudah didapatkan sebelumnya. Adapun data-data yang diperoleh dari survei langsung di lapangan berupa geometrik jalan, hambatan samping, dan volume kendaraan.

\subsubsection{Volume Lalu Lintas}

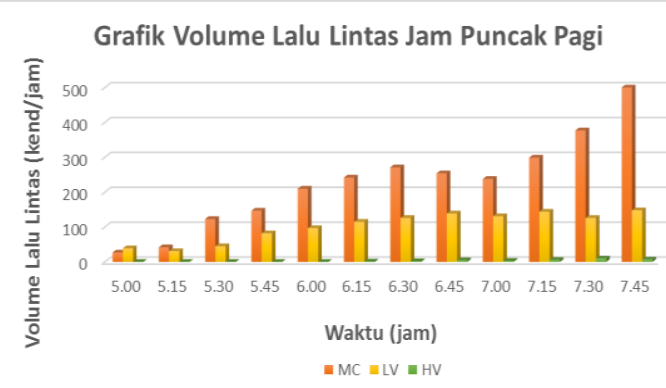

Gambar 4.1 Grafik Volume Lalu Lintas Jam Puncak Pagi Jalan Madukoro 


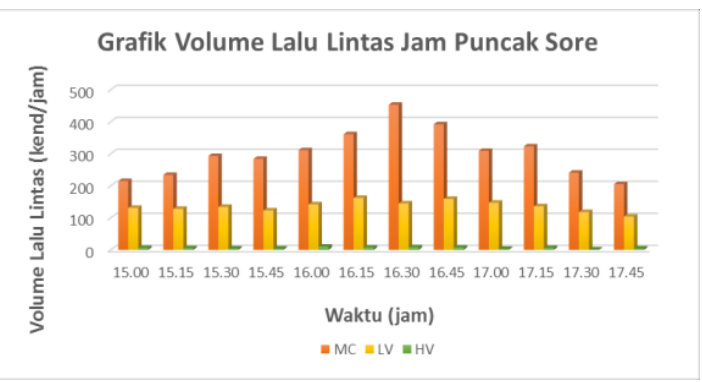

Gambar 4.2 Grafik Volume Lalu Lintas Jam Puncak Sore Jalan Madukoro

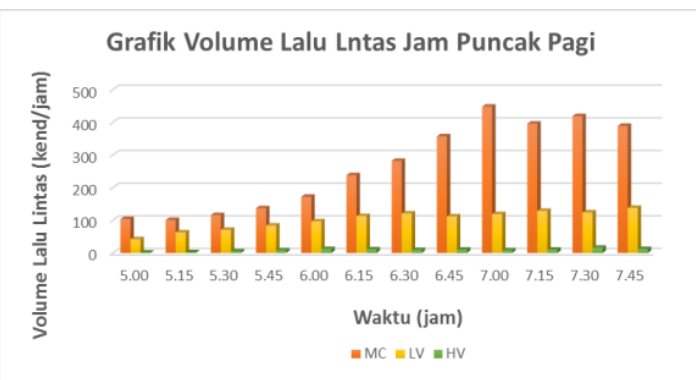

Gambar 4.3 Grafik Volume Lalu Lintas Jam Puncak Pagi Jalan Yos Sudarso

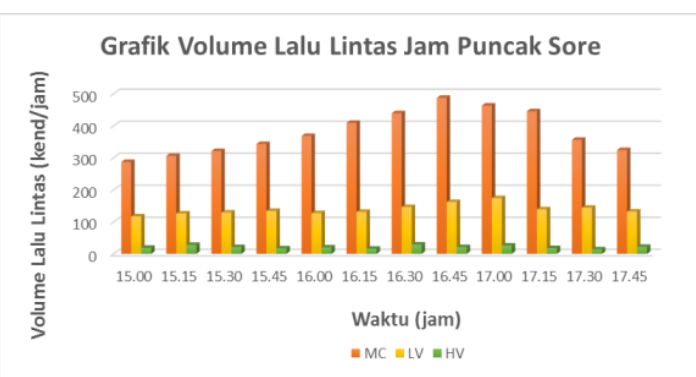

Gambar 4.4 Grafik Volume Lalu Lintas Jam Puncak Sore Jalan Yos Sudarso

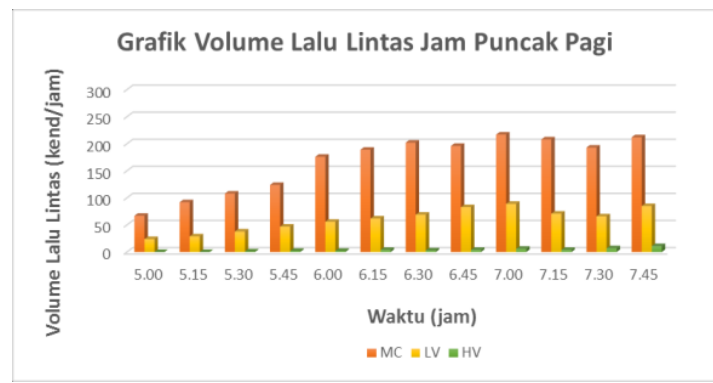

Gambar 4.5 Grafik Volume Lalu Lintas Jam Puncak Pagi Jalan Puri Anjasmoro Raya

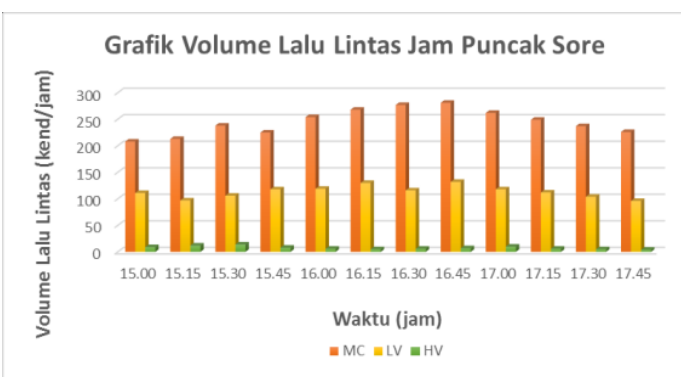

Gambar 4.6 Grafik Volume Lalu Lintas Jam Puncak Sore Jalan Puri Anjasmoro Raya

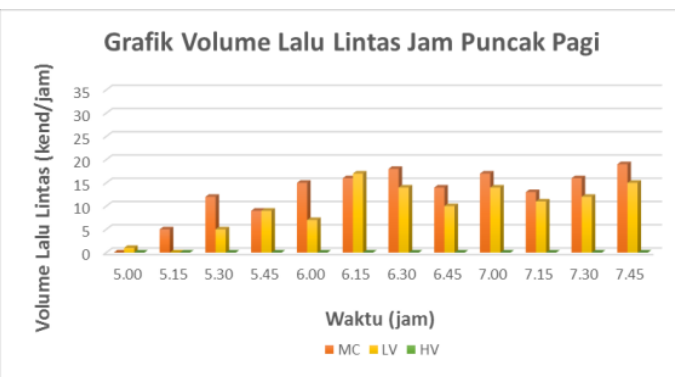

Gambar 4.7 Grafik Volume Lalu Lintas Jam Puncak Pagi Jalan Puri Eksekutif

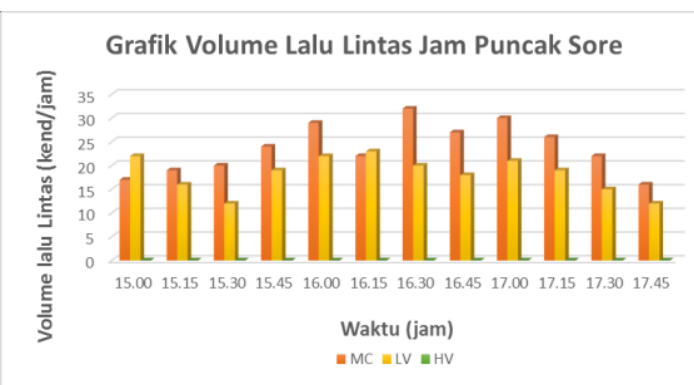

Gambar 4.8 Grafik Volume Lalu Lintas Jam Puncak Sore Jalan Puri Eksekutif

\subsubsection{Kapasitas Jalan}

Untuk menghitung kapasitas yang terjadi pada jam puncak volume lalu lintas di empat ruas jalan di sekitar bandara yang menjadi objek penelitian, dapat dilakukan dengan langkah-langkah sebagai berikut:

1. Menentukan Kapasitas Dasar

Menentukan nilai $\mathrm{C}_{0}$ dengan menggunakan Tabel 2.3, maka nilai $\mathrm{C}_{\mathrm{o}}$ untuk Jalan Madukoro dan Jalan Yos Sudarso per lajur adalah $1650 \mathrm{smp} / \mathrm{jam}$, 
untuk Jalan Puri Anjasmoro Raya nilai $\mathrm{C}_{\mathrm{o}}$ per lajur adalah $1300 \mathrm{smp} / \mathrm{jam}$, serta nilai $\mathrm{C}_{\mathrm{o}}$ untuk Jalan Puri Eksekutif per lajur adaah $1450 \mathrm{smp} / \mathrm{jam}$.

2. Faktor Penyesuaian Untuk Kapasitas

a.) Menentukan nilai $\mathrm{FC}_{\mathrm{SP}}$ dengan menggunakan tabel 2.4, segmen Jalan Madukoro memiliki tipe jalan 4/2, pada jam puncak pagi memiliki persentase $40 \%$ dan $60 \%$ pada sore hari, sehingga untuk faktor pemisah arah $\left(\mathrm{FC}_{\mathrm{SP}}\right)$ adalah 0,97 . Untuk Jalan Yos Sudarso juga memiliki tipe jalan 4/2, pada jam puncak pagi memiliki persentase $40 \%$ dan $60 \%$ pada sore hari, sehingga untuk faktor pemisah

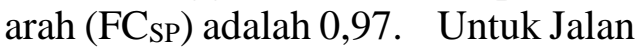
Puri Anjasmoro memiliki tipe jalan $2 / 2$, pada jam puncak pagi memiliki persentase $40 \%$ dan $60 \%$ pada sore hari, sehingga untuk faktor pemisah arah $\left(\mathrm{FC}_{\mathrm{SP}}\right)$ adalah 0,94 . Untuk Jalan Puri Eksekutif juga memiliki tipe jalan 2/2, pada jam puncak pagi memiliki persentase $40 \%$ dan $60 \%$ pada sore hari, sehingga untuk faktor pemisah arah (FCSP) adalah 0,94.

b.) Menentukan nilai $\mathrm{FC}_{\mathrm{w}}$ dengan menggunakan Tabel 2.5, lebar per lajur Jalan Madukoro adalah 3,5 m, maka nilai $\mathrm{FC}_{\mathrm{w}}=1,0$. Lebar per lajur Jalan Yos Sudarso adalah $4 \mathrm{~m}$, maka nilai $\mathrm{FC}_{\mathrm{w}}=1,08$. Lebar per lajur Jalan Puri Anjasmoro adalah 3,5 m, maka nilai $\mathrm{FCw}=1,0$. Lebar per lajur Jalan Puri Eksekutif adalah $3 \mathrm{~m}$, maka nilai $\mathrm{FC}_{\mathrm{w}}=1,0$.

c.) Menentukan nilai $\mathrm{FC}_{\mathrm{SF}}$ dengan menggunakan Tabel 2.6, lebar bahu jalan di Jalan Madukoro adalah 1,5 m, maka nilai $\mathrm{FC}_{\mathrm{SF}}=1,02$. Lebar bahu jalan di Jalan Yos Sudarso adalah 1,5 $\mathrm{m}$, maka nilai $\mathrm{FC}_{\mathrm{SF}}=1,02$. Lebar bahu jalan di Jalan Puri Anjasmoro adalah
$1 \mathrm{~m}$, maka nilai $\mathrm{FC}_{\mathrm{SF}}=0,92$. Lebar bahu jalan di Jalan Puri Eksekutif adalah 0,5 m, maka nilai $\mathrm{FC}_{\mathrm{SF}}=0,94$.

d.) Menentukan ukuran kota $\left(\mathrm{FC}_{\mathrm{CS}}\right)$ dengan menggunakan Tabel 2.7. Jumlah penduduk di Kota Semarang adalah 1.815.729 jiwa, maka diperoleh nilai $\mathrm{FC}_{\mathrm{CS}}$ sebesar 1,0.

3. Kapasitas

Menghitung nilai kapasitas dengan menggunakan persamaan:

$\mathrm{C}=\mathrm{C}_{\mathrm{o}} \times \mathrm{FC}_{\mathrm{w}} \times \mathrm{FC}_{\mathrm{SP}} \times \mathrm{FC}_{\mathrm{SF}} \times \mathrm{FC}_{\mathrm{CS}}$

a.) Nilai kapasitas di Jalan Madukoro

$\mathrm{C}=1650 \times 0,97 \times 1,0 \times 1,02 \times 1,0$

$\mathrm{C}=1632,51 \mathrm{smp} / \mathrm{jam}$

b.) Nilai kapasitas di Jalan Yos Sudarso

$\mathrm{C}=1650 \times 0,97 \times 1,08 \times 1,02 \times 1,0$

$\mathrm{C}=1763,11 \mathrm{smp} / \mathrm{jam}$

c.) Nilai kapasitas di Jalan Puri

Anjasmoro Raya

$$
\mathrm{C}=1300 \times 0,94 \times 1,0 \times 0,92 \times 1,0
$$

$\mathrm{C}=1124,24 \mathrm{smp} / \mathrm{jam}$

d.) Nilai kapasitas di Jalan Puri Eksekutif

$\mathrm{C}=1450 \times 0,94 \times 1,0 \times 0,94 \times 1,0$

$\mathrm{C}=1281,22 \mathrm{smp} / \mathrm{jam}$

Dari hasil perhitungan diperoleh hasil kapasitas yang sama untuk jam puncak pagi dan jam puncak sore. Hal ini dikarenakan faktor penyesuaian yang digunakan dalam perhitungan sama.

\subsubsection{Derajat Kejenuhan}

Setelah

kapasitas sesungguhnya diperoleh, selanjutnya dapat dihitung besarnya derajat Q kejenuhan dengan menggunakan persamaan $\mathrm{DS}=\mathrm{C}$, maka dapat dihitung besarnya nilai derajat kejenuhan di empat ruas jalan dibawah ini:

a.) Nilai derajat kejenuhan di Jalan Madukoro

Nilai Q pada jam puncak volume lalu lintas pagi hari (07.00 - 08.00) yaitu sebesar 944,95 smp/jam, sedangkan Q pada jam puncak volume lalu lintas sore 
hari (16.00 - 17.00) yaitu sebesar 1025,65 smp/jam.

Maka untuk jam puncak volume lalu lintas pagi hari, nilai DS adalah:

$\mathrm{DS}=\frac{\mathrm{Q}}{\mathrm{C}}$

$\mathrm{DS}=\frac{994,95}{1632,51}$

$\mathrm{DS}=0,58$

Untuk jam puncak volume lalu lintas sore hari:

$\mathrm{DS}=\frac{\mathrm{Q}}{\mathrm{C}}$

$\mathrm{DS}=\frac{1025,65}{1632,51}$

$\mathrm{DS}=0,63$

b.) Nilai derajat kejenuhan di Jalan Yos Sudarso

Nilai Q pada jam puncak volume lalu lintas pagi hari (07.00 - 08.00) yaitu sebesar 978,20 smp/jam, sedangkan Q pada jam puncak volume lalu lintas sore hari (16.30 - 17.30) yaitu sebesar 1192,30 smp/jam.

Maka untuk jam puncak volume lalu lintas pagi hari, nilai DS adalah:

$$
\begin{aligned}
& \mathrm{DS}=\frac{\mathrm{Q}}{\mathrm{C}} \\
& \mathrm{DS}=\frac{978,20}{1763,11} \\
& \mathrm{DS}=0,55
\end{aligned}
$$

Untuk jam puncak volume lalu lintas sore hari:

$\mathrm{DS}=\frac{\mathrm{Q}}{\mathrm{C}}$

$\mathrm{DS}=\frac{1192,30}{1763,11}$

$\mathrm{DS}=0,67$ c) Nilai derajat kejenuhan di Jalan Puri Anjasmoro Raya

Nilai Q pada jam puncak volume lalu lintas pagi hari (06.30 - 07.30) yaitu sebesar 538,15 smp/jam, sedangkan Q pada jam puncak volume lalu lintas sore hari (16.00 - 17.00) yaitu sebesar 808,80 smp/jam.

Maka untuk jam puncak volume lalu lintas pagi hari, nilai DS adalah:

$$
\begin{aligned}
& \mathrm{DS}=\frac{\mathrm{Q}}{\mathrm{C}} \\
& \mathrm{DS}=\frac{538,15}{1124,24} \\
& \mathrm{DS}=0,47
\end{aligned}
$$

Untuk jam puncak volume lalu lintas sore hari:

$$
\begin{aligned}
& \mathrm{DS}=\frac{\mathrm{Q}}{\mathrm{C}} \\
& \mathrm{DS}=\frac{808,80}{1124,24} \\
& \mathrm{DS}=0,71
\end{aligned}
$$

d) Nilai derajat kejenuhan di Jalan Puri Eksekutif

Nilai Q pada jam puncak volume lalu lintas pagi hari $(07.00$ - 08.00) yaitu sebesar 944,95 smp/jam, sedangkan Q pada jam puncak volume lalu lintas sore hari (15.45 - 16.45) yaitu sebesar 1025,65 smp/jam.

Maka untuk jam puncak volume lalu lintas pagi hari, nilai DS adalah:

$$
\begin{aligned}
& \mathrm{DS}=\frac{\mathrm{Q}}{\mathrm{C}} \\
& \mathrm{DS}=\frac{68,25}{1281,22} \\
& \mathrm{DS}=0,05
\end{aligned}
$$


Untuk jam puncak volume lalu lintas sore hari:

$$
\begin{aligned}
& \mathrm{DS}=\frac{\mathrm{Q}}{\mathrm{C}} \\
& \mathrm{DS}=\frac{110,75}{1281,22} \\
& \mathrm{DS}=0,08
\end{aligned}
$$

4.3 Perbandingan Kinerja Ruas Jalan Madukoro, Jalan Yos Sudarso, Jalan Puri Anjasmoro Raya, serta Jalan Puri Eksekutif Sebelum dan Sesudah Beroperasinya Bandara Yang Baru

Hasil perbandingan dari analisis data di atas adalah sebagai berikut:

\begin{tabular}{|c|c|c|c|c|}
\hline \multirow{2}{*}{ Waktu } & \multicolumn{4}{|c|}{ Nilai DS } \\
\cline { 2 - 5 } & $\begin{array}{c}\text { Jl. } \\
\text { Madukoro }\end{array}$ & $\begin{array}{c}\text { Jl. Yos } \\
\text { Sudarso }\end{array}$ & $\begin{array}{c}\text { Jl. Puri } \\
\text { Anjasmoro } \\
\text { Raya }\end{array}$ & $\begin{array}{c}\text { Jl. Puri } \\
\text { Eksekutif }\end{array}$ \\
\hline Pagi & 0,24 & 0,41 & 0,45 & - \\
\hline Sore & 0,39 & 0,48 & 0,55 & - \\
\hline
\end{tabular}

\begin{tabular}{|c|c|c|c|c|}
\hline \multirow{2}{*}{ Waktu } & \multicolumn{4}{|c|}{ Nilai DS } \\
\cline { 2 - 5 } & $\begin{array}{c}\text { Jl. } \\
\text { Madukoro }\end{array}$ & $\begin{array}{c}\text { Jl. Yos } \\
\text { Sudarso }\end{array}$ & $\begin{array}{c}\text { Jl. Puri } \\
\text { Anjasmoro } \\
\text { Raya }\end{array}$ & $\begin{array}{c}\text { Jl. Puri } \\
\text { Eksekuti } \\
\text { f }\end{array}$ \\
\hline Pagi & 0,58 & 0,55 & 0,47 & 0,05 \\
\hline Sore & 0,63 & 0,67 & 0,71 & 0,08 \\
\hline
\end{tabular}

Melihat hasil analisis data diatas, bila kita bandingkan kinerja ruas jalan di masing-masing ruas jalan baik sebelum dan sesudah bandara yang baru beroperasi mendapatkan hasil yang tidak terlalu jauh berbeda karena nilai DS $<1$ pada setiap ruas jalan

\section{PEMBAHASAN DAN SARAN 5.1 Kesimpulan}

Berdasarkan hasil analisis yang telah dibahas pada bab sebelumnya, maka dapat ditarik kesimpulan sebagai berikut:
1. Nilai derajat kejenuhan (DS) pada masa sekarang untuk masing-masing ruas jalan adalah 0,63 di Jalan Madukoro termasuk dalam tingkat pelayanan kategori C; 0,67 di Jalan Yos Sudarso termasuk dalam tingkat pelayanan kategori $\mathrm{C}$; 0,71 di Jalan Puri Anjasmoro Raya termasuk dalam tingkat pelayanan kategori C; 0,08 di Jalan Puri Eksekutif termasuk dalam tingkat pelayanan kategori A.

2. Kinerja ruas jalan yang berada di sekitar Bandara Jenderal Ahmad Yani Semarang masih berada dalam kondisi arus yang stabil, karena nilai derajat kejenuhan (DS) di masingmasing ruas jalan yang menjadi objek penelitian kurang dari satu.

3. Ruas jalan yang memiliki tingkat pelayanan terbaik adalah Jalan Puri Eksekutif dengan tingkat pelayanan kategori A, artinya kondisi arus bebas karena volume lalu lintas yang rendah. Pengemudi dapat memilih kecepatan yang diinginkan tanpa hambatan.

\subsection{Saran}

Adapun saran yang dapat dijadikan pertimbangan untuk mengatasi masalah yang terdapat pada ruas jalan tersebut, yaitu:

1. Melihat padatnya jumlah kendaraan yang melintas di empat akses jalan yang menjadi penghubung Kota Semarang menuju Bandara Internasional Jenderal Ahmad Yani, sebaiknya kondisi jalan harus selalu dijaga dan apabila ada jalan yang rusak Pemerintah Kota Semarang segera memperbaikinya demi kenyamanan pengguna jalan.

2. Sebaiknya Pemerintah Kota Semarang menambah koridor BRT Trans Semarang menuju Bandara 
Internasional Jenderal Ahmad Yani Semarang untuk mempermudah masyarakat yang akan pergi ke bandara tanpa menggunakan kendaraan pribadi.

\section{DAFTAR PUSTAKA}

Alamsyah, A.A. 2003. Rekayasa Jalan Raya. Universitas Muhamadyah Malang (UMM). Malang.

Badan Pusat Statistik Kota Semarang. 2018. Semarang Dalam Angka 2018. BPS Provinsi Jawa Tengah, diperoleh dari situs internet https://semarangkota.bps.go.id/pu blication/2018/08/10/f32914aa8d7d0 f43bad0946a/profil- kependudukankota-semarang-2017.html. Diunduh tanggal 20 Agustus 2018, pukul 10.00 WIB.

Departemen Pekerjaan Umum. 1997. Manual Kapasitas Jalan Indonesia (MKJI), Jakarta: Dirjen Bina Marga.

Dirjen Perhubungan Darat, Direktorat BSLLAK. 1999. Rekayasa Lalu Lintas. Jakarta.

Highway Capacity Manual. 2000. Metric Units, Transportation Research Board (TRB), National Research Council. Washington D.C.

Peraturan Daerah Kota Semarang No. 3 Tahun 2016 Pasal 4 Huruf d. Semarang.

Sugeng, R. 2018. Rekayasa dan Manajemen Lalu Lintas, Teori dan Aplikasi. Yogyakarta: Universitas Janabadra.
Sukirman, S. 1994. Dasar-Dasar Perencanaan Geometrik Jalan Raya, Nova, Bandung.

Tamin, O.Z. 2000. Perencanaan dan Pemodelan Transportasi, Edisi Kedua. Bandung: Institut Teknologi Bandung (ITB).

Undang-Undang Republik Indonesia No. 38 Tahun 2004. Tentang Jalan (Lembaran Negara Republik Indonesia Tahun 2004 Nomor 132). Jakarta. 